\title{
The white of the 20th century: an explorative survey into Dutch modern art collections
}

\author{
B. A. van Driel ${ }^{1,2,3^{*}}$ (D, K. J. van den Berg ${ }^{2}$, J. Gerretzen ${ }^{4}$ and J. Dik ${ }^{3}$
}

\begin{abstract}
White pigments were abundantly used in 20th century paintings, and relate to several degradation risks such as titanium white mediated photocatalytic binder degradation or zinc soap formation. Knowledge about the white pigments that were used is essential for risk assessments of 20th century collections. In this study, a representative set of 179 paintings in Dutch modern art collections were analyzed by portable X-ray fluorescence spectrometry. Subsequent explorative data analysis was performed, supported by qualitative findings from 140 home-made reference samples. Micro-samples were further investigated by X-ray diffraction and scanning transmission electron microscopy to gain information about crystal structure and surface coating. This study reveals that Dutch 20th century artists were hesitant to use titanium white. In the Netherlands, the use of this pigment is observed convincingly from the 1970s onward and initially mostly in non-oil binders. Additionally, lead white was used until late in the 20th century for paints and grounds but rarely mixed with titanium white in paints. The study also indicated that many CoBrA artists used zinc white, underlining the risk of degradation due to soap formation. Furthermore, this study highlights the different production processes of titanium white. Through the association of titanium with niobium, an impurity only present for sulfate processed pigments, the production process can be identified. The absence of niobium indicates the presence of rutile and is thus a sign of paint stability, as well as a 'post 1959 ' dating. This explorative study illustrates the value of a combination of data analysis approaches, which includes assessment of spectra as well as descriptive, bivariate and multivariate analysis, for medium-sized datasets gathered at similar conditions.
\end{abstract}

Keywords: White pigments, $\mathrm{TiO}_{2}, \mathrm{XRF}$, 20th century, Modern art, Principal component analysis

\section{Introduction}

This study investigates the use of different white pigments in the Netherlands during the 20th century. The 20th century was a century of great technological achievements, of shattering world wars and of modern art and architecture: 'art for the purpose of art.' Within this era, Le Corbusier popularized white in his modernist architecture of the 1920s and with Kazimir Malevich's painting "White on white" (1918), white became a defining icon of modernism. Almost simultaneously, in November of 1918, industrial production of titanium white composite pigments began in Fredrikstad, Norway

\footnotetext{
${ }^{*}$ Correspondence: b.van.driel@rijksmuseum.nl

${ }^{1}$ Rijksmuseum Amsterdam, Hobbemastraat 22, 1071 ZC Amsterdam, The Netherlands

Full list of author information is available at the end of the article
}

[1]. Around the same time, health and safety problems related to lead white were discovered, leading to a ban or restriction (Geneva White Lead Convention) of the use of lead white for interior painting between 1905 and 1930 in most countries [2]. Although lead white was on the market (pure or mixed) in the 20th century, Bacci et al. report, based on literature, that its presence dropped from $100 \%$ in the early 20 th century to $10 \%$ by 1945 , and it nearly disappeared after the second world war [3, 4]. Less effective earlier alternatives to lead white such as lithopone (a co-precipitate of barium sulfate and zinc sulfide) were eventually and after heavy competition [5], replaced by the new and superior calcium based rutile titanium white [2].

\footnotetext{
${ }^{1}$ A 19th Century expression related to modernism-'L'art pour l'art' in French.
} and indicate if changes were made. The Creative Commons Public Domain Dedication waiver (http://creativecommons.org/ publicdomain/zero/1.0/) applies to the data made available in this article, unless otherwise stated. 


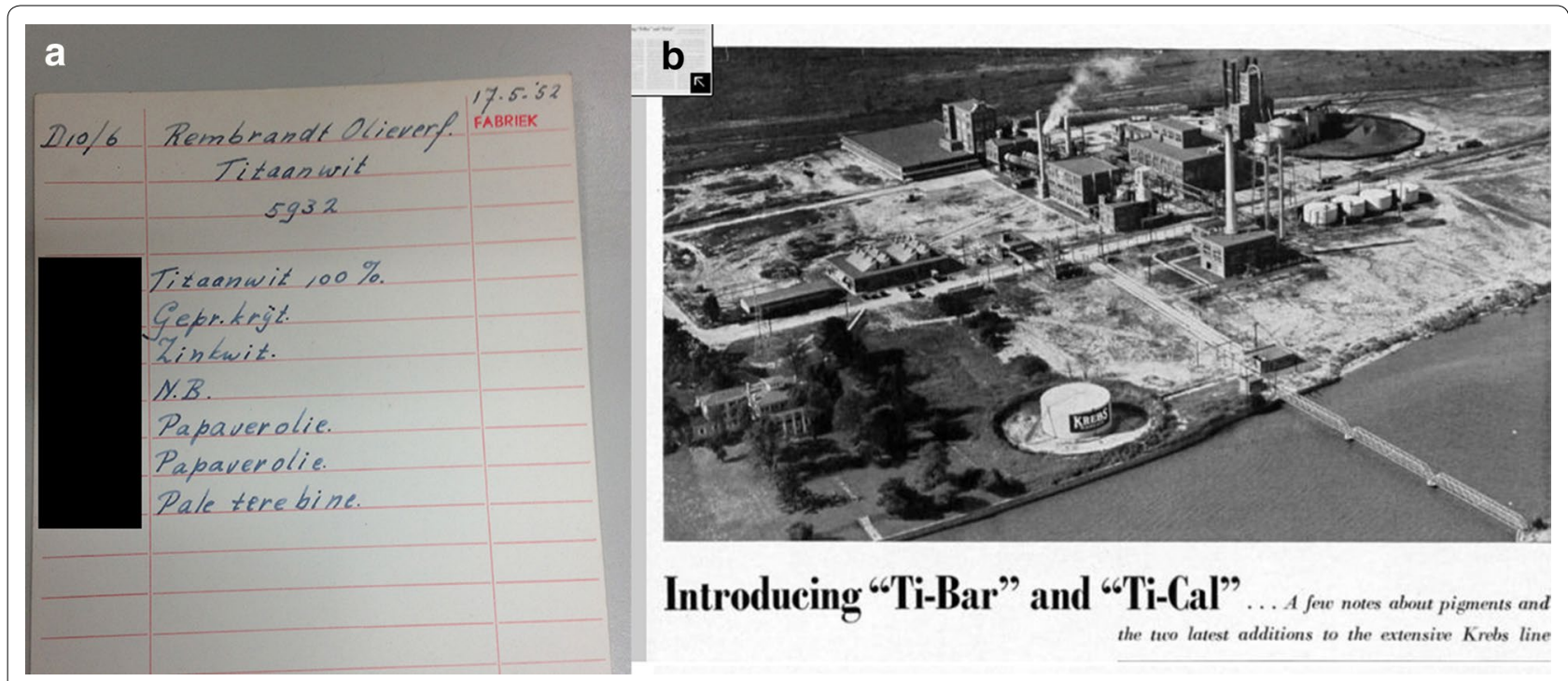

Fig. 1 a 1952 Recipe for titanium white from the archive of Royal Talens (Apeldoorn, the Netherlands) and $\mathbf{b}$ an article concerning titanium white composite pigments from the Dupont magazine 1935 [14]

Zinc white was marketed by Winsor and Newton in 1834 and was thus an earlier alternative for lead white. However, initially zinc white was not very popular. This is due to the price difference (zinc white being more than four times more expensive than lead white at the turn of the 18th century), as well as the lack of hiding power. Zinc white only became popular after 1850 [6]. After the introduction of titanium white, zinc white continues to be used as a pure pigment. Additionally, it is used in titanium white paints and colored paints to adjust the tinting strength [7].

In the early 1940s, Piet Mondriaan painted his famous Broadway Boogie Woogie and Victory Boogie Woogie, reportedly using Permalba $[8,9]$, a renowned American titanium white [7]. However, Mondriaan complained about the properties of titanium white, and he is assumed to have preferred lead white [10]. The discussion about the best choice of white has continued since the days and complaints of Mondriaan. Present day artists still wonder and do small tests to compare paint characteristics of white paints [11-13]. The white pigments all have their specific benefits and drawbacks. Lead white oil paint is toxic but has brilliance, a nice consistence and a faster drying time. Titanium white oil paint has high opacity but is said to have a higher tendency to yellow and zinc white oil paint dries to a brittle film, although it is beneficial due to its transparency and price. Combining titanium and zinc white makes successful formulations and is often found in recipes in the United States as well as in Europe, see Fig. 1a [7].
In the 1920s most commercial titanium white pigments are composite pigments from the plant in Fredrikstad or Niagara Falls, see Fig. 1b (Additional file 1: Table S1). After 1926, the production of pure anatase pigments is reported [1]. In the 1940s, surface treatments and rutile pigments enter the market, but the main pigments continue to be composite pigments until they are eventually discontinued, around 1970 [5], due to their incompatibility with water-borne paints [15].

The evolution of the use of white pigments is undoubtable country dependent, related to novel developments and patents and connected to marketed pigments as well as artist preference. While trends of white pigment use have been identified, they seem to have a geographical bias toward the United States [1,5].

This study intends to geographically specify and extend information about the use of white pigment by non-invasive and micro-invasive analysis of 20th century paintings mainly by Dutch artists. The driving force was the need to know the extent of use of titanium white in relation to its risk of photocatalytic degradation [16-18]. The timing of titanium white becoming popular amongst artists is important, as it possibly relates to the quality of those pigments. Similarly, knowing how much zinc white has been used may help us understand and estimate the extent of the zinc soap degradation risks of modern collections [19].

In this study, portable X-ray fluorescence spectrometry (pXRF) was used to investigate the white pigments used in modern paintings in Dutch art collections. Portable 
XRF was chosen for its general availability (both to the authors and also increasingly for museums), for its ease of use and its completely non-invasive character. The main drawback of XRF is that the distinction between rutile or anatase pigments cannot be made [20,21]. Furthermore, pigment coating materials, such as alumina and silica, cannot be detected. To account for the limitations of pXRF on paintings, a selection of titanium containing micro-samples are investigated by $\mathrm{X}$-ray diffraction (XRD) and scanning transmission electron microscopy with energy dispersive spectroscopy (STEM-EDX).

Portable XRF, while being widely used for the investigation of paintings [21-24], should be interpreted with care as physical processes such as attenuation, absorption and matrix effects can influence the outcome. Furthermore, so-called escape peaks, scatter peaks, peaks originating from the instrument as well as overlapping peaks can complicate interpretation, which is especially challenging when investigating non-homogeneous multilayer materials such as paintings. Given these limitations, while peak areas are used to facilitate interpretation, the results of this study should be considered as qualitative, showing merely trends. A notorious difficulty, applicable to white paint, is the overlap between $\mathrm{Ti}$ K-lines and Ba L-lines [21]. This overlap can challenge the identification of titanium when barium is also present [7]. Hence, in this study, the applicability of PyMCA (Python MultiChannel Analyzer) [25] for deconvolution of these overlapping peaks is evaluated with self-made reference paints. As comparison of XRF spectra can be challenging, more and more accounts of additional multivariate data analysis are reported, mostly on processed data extracted from spectra (such as elemental concentrations) [26-31]. It is in this scope that, principal component analysis (PCA) has been used in this paper to enhance the interpretability of the pXRF dataset.

To summarize, the goal of the present study is to gain insight into the use of 20th century white pigments in Dutch collections. This is performed using a combination of analytical techniques and data analysis approaches, focused on the development over time rather than on singular paintings. To that end, we use pXRF on paintings and reference samples, supported by XRD and STEM-EDX on particular micro-samples. The data analysis approaches include spectral assessment, as well as descriptive, bivariate and multivariate methods. The gained insight is useful for risk assessment of paintings at modern art institutions, especially in relation to degradation phenomena occurring in paints containing the different white pigments.
Table 1 Overview of the artwork dataset

\begin{tabular}{lcl}
\hline Art collection & \multicolumn{2}{l}{$\begin{array}{l}\text { Number of investigated paint- } \\
\text { ings }\end{array}$} \\
\cline { 2 - 3 } & XRF & XRD and or STEM-EDX \\
\hline AMC art collection & 6 & 0 \\
Cobramuseum Amstelveen & 35 & $1^{\text {a }}$ \\
Gemeentemuseum Den Haag & 30 & $1^{\text {a }}$ \\
ING art collection & 11 & 0 \\
Museum Prinsenhof Delft & 16 & 0 \\
Bouwfonds art collection & 16 & 8 \\
RCE art collection & 35 & 1 \\
Stedelijk museum Schiedam & 25 & 0 \\
Other & 5 & $8^{\text {a }}$ \\
Total & 179 & $10^{\text {a }}+9$ \\
\hline
\end{tabular}

a Indicates the paintings that were analyzed with pXRF and XRD or STEM-EDX

\section{Experimental}

\section{Dataset}

In total, the dataset contains 189 paintings, 179 of which were analyzed by pXRF. Micro-samples were taken from nine out of these 179 paintings. Ten paintings could not be analyzed by pXRF due to accessibility to the artwork and are only available as micro-samples. The micro-samples (19 in total) were analyzed by XRD and/or STEMEDX. Data for this study was gathered over the course of 3 years at several art institutions aiming to gather a representative dataset of 20th century paintings. The data gathering procedure is representative for painting specific analysis performed in museum studios. The art institutes include Dutch company art collections as well as several Dutch modern art museums (see Table 1), resulting in a geographical focus towards the Netherlands. The goal when building the dataset was to avoid bias towards specific artists or towards a specific artistic movement. This was achieved by arbitrarily choosing 20th century paintings containing white, spread between 1920 and 2000. The selection of artworks was left to the discretion of the collection keepers under the conditions that the paintings have white areas, are unframed and were painted after 1920. Each collection keeper approached this differently. For instance the collection database was searched for the word 'white' and filtered for the time period. In other instances physically accessible paintings in a collection or office buildings were chosen, taken into account radiation safety. The number of works that could be measured was limited by the time the institutions allowed access to the collections (mostly 1-3 days) and by whether the paintings were collected in a single room or hanging throughout a building.

While being balanced over time, with more than 20 paintings per decade from the 1940s to the 1980s, and 
geographically focused on the Netherlands, the dataset is unavoidably art historically limited. Some art historically significant artists or artistic movements, such as Mondriaan or the neo-realistic movement, are missing from the pXRF dataset. However, our selection does reflect a continuous chronology of whites used between 1920 and 2000. In other words, while not being art-historically complete our selection is chronologically and geographically representative.

The size of the dataset allowed for a combination of data analysis approaches. It is small enough to assess the spectra individually and large enough to identify interesting trends.

A second data set (the reference set), composed of selfmade paints, was analyzed in this study. It was built with the aim to reach better spectral interpretation following qualitative guidelines specifically related to peak ratios, peak overlap and layering effects. The need for improved spectral interpretation is due to the large number of nonexpert users in museums and was highlighted by a pXRF round robin in 2009. The round robin indicated that while $65 \%$ of the laboratories identified the correct elements, only 40\% reached a correct interpretation [21].

The reference set was based on readily available paints from other studies containing mixtures of different types of titanium white, titanium white mixed with zinc white, barium sulfate or calcium carbonate $[16,18]$, as well as combinations of single-pigment layers (unpublished study). The dataset was extended with several crucial samples including layer combinations and mixtures with lead white and a calibration set for the $\mathrm{Ba}-\mathrm{L} / \mathrm{Ti}-\mathrm{K}$ deconvolution. The reference samples were painted either on Melinex or on modern prepared canvas board and attached with double-sided tape to a Perspex board for pXRF analysis to limit background detection.

Both complete datasets are summarized in Additional file 1: Tables S2, S3.

\section{Analysis \\ Portable X-ray fluorescence spectrometry}

The paintings were analyzed using a Bruker III-SD pXRF. Two different instruments of the same type were used due to instrument availability during the project. Measurements were taken in two slightly different settings for the two instruments suitable for the detection of the elements of interest in paintings: ${ }^{2}$

\footnotetext{
2 The use of different instrument settings was an unintended error. The time between using the first and the second instrument was substantial, due to the malfunctioning of the first instrument. Since time of analysis can easily be corrected and 10 or $30 \mathrm{~s}$ is both appropriate for the detection of the elements of interest, changing the time from 10 to $30 \mathrm{~s}$ was a minor concern. Furthermore, the second instrument had a glitch and only functioned in the $40 \mathrm{kV}, 15 \mu \mathrm{A}$ setting. These different operating procedures are actually representative of how data would be collected at different museums in an uncoordinated/painting specific manner.
}

- Bruker Tracer III-SD (1) $40 \mathrm{kV}, 10 \mu \mathrm{A}$, air, $10 \mathrm{~s}$, no contact, $\mathrm{Ti} / \mathrm{Al}$ filter.

- Bruker Tracer III-SD (2) 40 kV, $15 \mu \mathrm{A}$, air, $30 \mathrm{~s}$, no contact, Ti/Al filter.

The Ti/Al filter was used because it renders pXRF more suitable for the analysis of elements from titanium to silver. Using the filter provides a reduced background in the low energy region and eliminates, for instance, the $\mathrm{Rh}-\mathrm{L}$ and Ar-K lines originating from the tube and the air (Additional file 1: Figure S1).

Depending on the number of artworks to be measured in 1 day, and on specific questions from the collection, ${ }^{3}$ we measured a different number and selection of areas per painting. For each painting, at least two different areas of white paints were analyzed. Additionally, the following areas were occasionally analyzed: impasto areas, areas of paint ground, the back of the painting and colored areas. Furthermore, in some cases, additional measurements were performed without the $\mathrm{Ti} / \mathrm{Al}$ filter. Therefore the number of spectra per artwork is variable and averaging of peak areas is performed before data analysis.

The reference samples were all measured two times, some of which were additionally analyzed without the Ti/ Al filter.

\section{$X$-ray diffraction and STEM-EDX}

The crystalline phases of individual micro-samples were analyzed by XRD using a Discover D8 microdiffractometer with a general area detection diffraction system (GADDS) two dimensional detector (Bruker AXS, Karlsruhe, Germany). The samples were measured without preparation on a concave microscope slide. Diffractograms were acquired in reflection mode using $\mathrm{Cu}-\mathrm{K} \alpha 1$ as primary radiation $(40 \mathrm{kV}, 30 \mathrm{~mA})$. The GADDS software was used for azimuthal integration of the two-dimensional XRD pattern in order to obtain a one-dimensional 2theta diffractogram suitable to perform a PDF library search on, using the Bruker AXS Eva software, for phase identification.

Bright field images of the powders were collected on a JEOL 2010F FEG-TEM equipped with a STEM unit and ThermoNoran EDX detector for elemental mapping. Samples were prepared by dipping a lacey $\mathrm{C}$ coated $\mathrm{Cu}$ TEM grid in the powder and subsequently removing the excess of powder.

\section{Data exploration}

Data analysis was performed with the primary aim to investigate when titanium white became popular among

\footnotetext{
${ }^{3}$ To return the favor of allowing us access we offered collections analysis to anser questions about specific paintings.
} 
artists working in the Netherlands in the 20th century. The exploration of the data was performed using a semiquantitative approach which combines spectral investigation of painting and references, with descriptive, bivariate and multivariate analysis. The qualitative results or trends obtained with principal component analysis in this study could be obtained and confirmed by descriptive and bivariate analysis as well. However, PCA is used here mainly as a visualization tool, because it is able to provide an interpretable summary of the data in two dimensions.

Data analysis was performed on deconvoluted elemental peak areas $[30,31]$, which were averaged, normalized and time and threshold corrected. This procedure is largely automated making use of PyMCA and Microsoft Excel. The method was chosen because it is easily interpretable and physically relevant. Data analysis on (corrected) raw spectra, which contain more information [26, $32,33]$, as well as the use of other types of multivariate analysis $[34,35]$, may result in more detailed differentiation of paints. However, these methods fall outside the scope of our study at this explorative stage.

\section{Deconvolution}

PyMCA was used for batch spectral deconvolution. An iterative approach was followed to find a suitable deconvolution configuration, starting with all of the known parameters and subsequently testing and adjusting the configuration (Additional file 1: Figures S2-S10). The goal was to find an appropriate deconvolution for the overlapping barium L-lines and titanium K-lines. Evaluation of the deconvolution, performed on reference paint outs of $\mathrm{TiO}_{2} / \mathrm{BaSO}_{4} /$ oil mixtures showed to be very accurate (Additional file 1: Figures S11-S13).

In this study we analyzed the peak areas calculated through spectral deconvolution. In other words, each variable is a peak area related to a specific element. The peak area is the sum of the areas under all elemental K-peaks or L-peaks respectively [25]. Using the peak area, rather than the height, is preferential because it is not affected by the spectrometer resolution but only by the number of X-ray photons detected. Ideally, the peak area, while related to the concentration in homogeneous samples, needs to be adjusted using an element specific calibration constant and a matrix specific correcting term which accounts for the matrix effects such as absorption and enhancement. Elemental concentration were not calculated in this study, given the mistakes it would inherently cause, because we are dealing with inhomogeneous and layered structures [20].

\section{Post-treatment}

Time and threshold correction Before data analysis, all peak-areas produced by PyMCA were corrected for the measurement time and for a manually set threshold value. The threshold values were determined by identifying the minimum peak area for which a peak was still visible in the spectrum. This was done with the intention only to analyze variables that conservators and scientists in museums could visually extract from the spectrum. A list of the used threshold values can be found in Additional file 1: Tables S5 and S6.

Averaging The full dataset contains about 1000 spectra including multiple spectra from the same artworks. The approach in this explorative study was to average the peak areas of multiple spectra from the same artwork. In different data subsets, the spectra of all the white areas, the spectra of all the colored areas, the spectra of all the white impastos or the spectra of all the areas of ground were averaged. This procedure may go at the expense of information such as the presence of different white paints on the same painting which could be of interest for a follow up study. ${ }^{4}$

Normalization The average counts per second can vary drastically per element depending on the energy of the emitted photons. In order to make the values more comprehensible, they were normalized by division by the maximum peak area, for selected subset analyses. This results in normalized peak areas where ' 1 ' is the main peak of the spectrum, and the other values are the fraction of the main peak. Hence, a peak area of ' 1 ' for titanium and '0.9' for zinc indicates that visually (raw spectrum) the peaks are nearly equal in size. This procedure was performed to enhance the interpretability of the results. It is important to remember that XRF is not quantitative in terms of elemental concentration and peak areas are also influenced by element sensitivity of the instrument and instrument settings.

Error The measurement error is negligible in comparison with the induced error originating from paint heterogeneity and post-processing. All the samples in the reference set were measured twice in order to get a better understanding of the size of this induced error. Between each measurement, the instrument was removed from the paint surface and repositioned, to induce the expected variability in measurement distance. This procedure leads

\footnotetext{
${ }^{4}$ Another approach is to average the spectra prior to deconvolution. Additionally, for the future a smart averaging algorithm could be developed separating the different types of paint on one painting and only averaging those similar to one another.
} 
to an error between 5 and $20 \%$ of the peak area, based on the average of the standard deviations of the titanium $K$ peak area of each set of two measurements. The same error holds for elemental detection limits that were investigated for an instrument from the same manufacturer as used in this study by Van der Snickt et al. [36].

\section{Data analysis}

In this study, we used a combined data analysis approach to explore the data with the main aim to determine when titanium white became popular among artists in the Netherlands. This approach involves descriptive, bivariate and multivariate analysis and has an explorative rather than exhaustive character. These analyses were performed in an iterative, back and forth process between descriptive or bivariate analysis and multivariate analysis. The full dataset, at different stages of post-processing, as well as subsets of the data were explored, until the research question could be answered in an satisfying way.

Descriptive and bivariate analysis Descriptive and bivariate analyses were performed either by counting paintings with specific elements in specific decades or by investigating the relation between two specific elements in a data (sub)set in scatterplots.

Principal component analysis Principal component analysis (PCA) was performed using a Python script in Jupyter notebook. All data have been mean centered prior to analysis. Principal component analysis of the full dataset indicated that the variance between the two different instruments is negligible if corrected for the time of analysis. This was done by visually comparing the shape of the PCA scores in the first two dimensions when PCA was applied to the data of both instruments separately. Because the datasets were randomly chosen by collections, both sets represent a similar group of paintings with a limited bias towards a decade, paint type or artist and may thus be compared.

\section{Reference paint outs}

Qualitative insights were gained from the spectral investigation of the reference paint outs (Additional file 1: Figures S14-S19) which can be used to interpret the paintings results. These insights are already detailed in the current section, given their applicability for data interpretation of the paintings dataset.

One of the main guidelines originates from the different element sensitivity of titanium and zinc. For pure metals the sensitivity for titanium was shown (L. Megens, Unpublished research) to be five times less than the sensitivity for zinc, using the Bruker III-SD instrument. The sensitivity is further distorted when the $\mathrm{Ti} / \mathrm{Al}$ filter is used, as this affects the sensitivity for titanium stronger than for zinc. Reference paint outs of equal volume titanium white, zinc white mixtures indicate that the titanium peak area is ten times lower than the zinc peak area (Additional file 1: Figure S11). This was shown by the analysis of six different mixtures resulting in the following linear fit: $[T i /(T i+Z n)]_{\text {measured }}=0.2[T i /(T i+Z n)]_{\text {real }}$, which can be solved by a peak area ratio of 0.11 [Ti] to 1 [Zn]. This is important information when interpreting an XRF spectrum visually and will be important information for the clustering of the PCA results. A combination of both peaks can also be caused by a layered paint structure with a thin ${ }^{5}$ brushstroke of titanium white on top of a zinc white layer. The intensity of the signal from the underlying zinc layer depends on the thickness and pigment content of both layers. The references show that when the titanium top layer reaches 'impasto' thickness (mm range), the zinc signal is completely absorbed. On the other hand, the combination of titanium and zinc in one spectrum cannot be caused by a layer of $\mathrm{ZnO}$ paint on top of $\mathrm{TiO}_{2}$ paint. This was shown by reference samples with a thin brushstroke of zinc white (or lead white) that show complete absorption of the sublayer Ti signal. Given that, at this explorative stage, we work with averages of spectra from different white areas, the combination of $\mathrm{Ti}$ and $\mathrm{Zn}$ in an artwork in this study can also relate to the use of different white paints in different areas of the painting.

\section{Results and discussion}

The trends resulting from the data exploration are discussed in relation to their impact on degradation risk and in relation to material/market knowledge acquired at several archives and in discussion with paint manufacturers. The use of white pigments in the 20th century will first be discussed based on general trends and specific artists. The results will be concluded with the identification of characteristic trace elements of interest.

\section{Introduction of $\mathrm{TiO}_{2}$ by Dutch artists}

It was commonly assumed, based on the occurrence of $\mathrm{TiO}_{2}$ in artworks from the United States [1, 5, 7], that $\mathrm{TiO}_{2}$ was used by artists almost as soon as it was taken into production. However, the present dataset suggests that a different trend was followed by Dutch

\footnotetext{
${ }^{5}$ In this study we did not quantify the layer thicknesses of our references given their qualitative assessment. Thin indicates a single brushstroke, while thick indicates an obvious impasto with a thickness in the $\mathrm{mm}$ range. The authors underline the value that an indepth quantified reference dataset for XRF interpretation by non-experts would have, however this falls outside the scope of this work.
} 


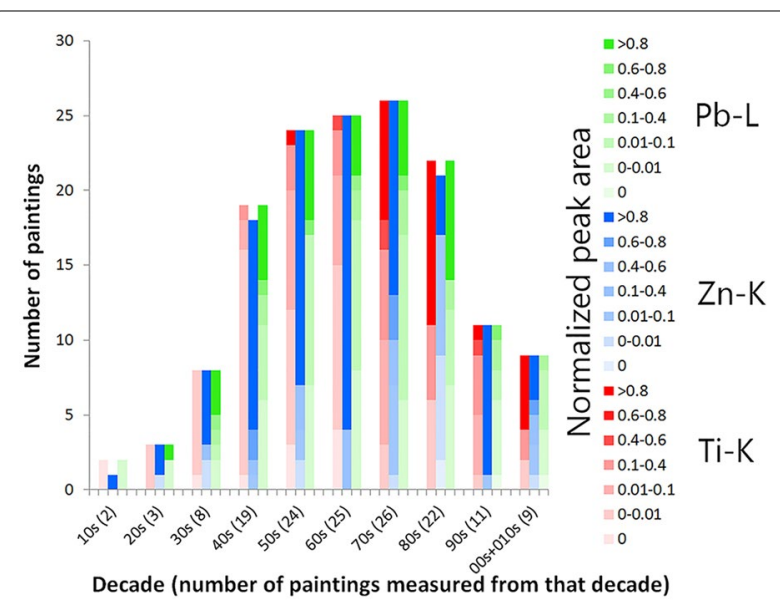

Fig. 2 Number of paintings containing a certain normalized content of zinc, titanium and lead, plotted by decade

artists. Figure 2 shows the number of paintings containing different peak areas of titanium, zinc and lead over the decades.

As discussed in the previous section, a normalized $\mathrm{Ti}$ peak area of 0.1 , with a main peak of $\mathrm{Zn}$ relates to a mixture, a layered structure or the use of multiple different paints. Figure 2 shows the convincing introduction of titanium white in the 1970s, while the pigment was already in production since the twenties. Earlier, starting in the fifties, mixtures or layers of titanium and zinc white can be found. The timing is in line with findings from the Royal Talens archive in Apeldoorn [37], where it was found that artists' oil paints containing titanium white were only marketed in 1952 for the Dutch market, while the first test batch was already produced in the thirties [7]. For the French market, Royal Talens marketed titanium white oil paints already in 1950, possibly as competition for 'Société Lefranc' and 'Société Bourgeois', that sold titanium white paints since the twenties [1]. While the relative absence of early titanium white in Dutch oil paints can be considered to be a good sign regarding degradation risk, it does not directly mean stable pigments were used from the seventies onward [1,5]. An example is paint manufacturer Royal Talens, that only switched to rutile for oil paints in the nineties (personal communication with Bert KleinOvink, Royal Talens) and still uses anatase for gouache today (confirmed by XRD analysis). Furthermore, Laver notes that "Due to their greater whiteness early products based on anatase were retained for many years after rutile pigments were introduced." [1]. However, it is important to realize that treated anatase pigments were also brought to the market and may have been used in late 20th century paints again reducing the degradation risk [38]. For instance, the pigment 'Tiofine A20' is often reported as titanium white pigment in Royal Talens recipes. The reference collection of the Cultural heritage agency of the Netherlands has a pigment labelled 'Tiofine', and while this may not be the same pigment, it does come from the same manufacturer. This pigment, shown to be anatase by XRD analysis, showed in STEM-EDX analysis to have a partial $\mathrm{Al} / \mathrm{Si}$ coating which would reduce the pigments photocatalytic activity.

We can only speculate about the reason for the slow rise of titanium white in Dutch oil paintings. Warnings were published about the yellowing of titanium white in oil paints [1, 39-41] possibly creating some reluctance for the use by artists. In the meantime, the yellowing problems were partly resolved by mixing titanium white with zinc white. Manufacturers such as Webber in the United states used zinc white additions early on and marketed their product 'Permalba' as "Brilliant...Permanent... and easy to handle".

Titanium white is not only absent in the white paints but also in the colored paints. Due to the high refractive index of titanium white, zinc white was preferred at Royal Talens to adjust the hue of a color paint tube (personal communication Bert Klein-Ovink). This is confirmed in the present dataset. Of all the (averaged) measurements of colored paints, 25 have lead as the main peak, 50 have zinc as the main peak and only 10 have titanium as the main peak. The latter are likely related to non-oil paintings. This suggests that, while white oil paints may be at risk for photocatalytic degradation, this risk is minor for $\mathrm{TiO}_{2}$-induced color fading.

Furthermore, most of the paintings with $\mathrm{Ti}-\mathrm{K}$ as the main peak are made with non-oil binding media such as acrylics, tempera and gouache. This is in line with XRD analysis of reference gouache, acrylic and tempera paint outs containing for the most part titanium white and fillers. It is understandable since both zinc white and lead white are not stable in, e.g. acrylic emulsion paints [1]. Furthermore, additional confirmation is found in archival recipes at Royal Talens of pure titanium white waterborne paints without the addition of any zinc white (van den Berg, unpublished research).

Figure 2 does not only shows the slow rise of titanium white and the ubiquitous use of zinc white, it also indicates the slow decrease of lead white. Until the eighties, it is found as the main element in some paints. This is in stark contrast with reports stating that lead white nearly disappears after World War 2 [3]. Additionally, analyzing a subset of painting grounds (Fig. 3) further confirms the use of lead white for grounds far into the twentieth century. In the Netherlands, lead white was banned from interior painting as early as 1939 [42, 43]. However, protective regulations for people working with lead white were only implemented in 1988, and a full ban of lead 


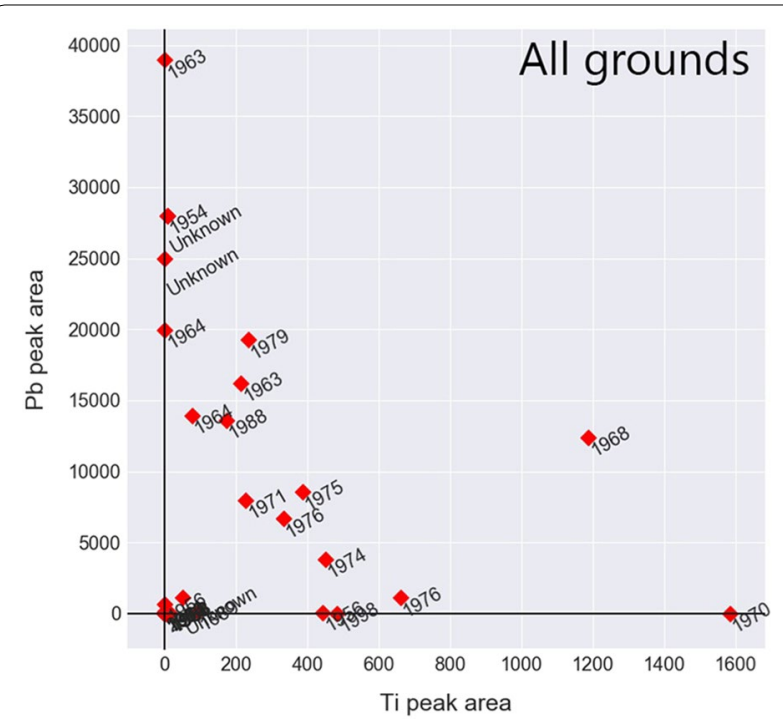

Fig. 3 Scatter plot of non-normalized lead L vs titanium $K$ peak areas of all grounds, labelled by year

white for outdoor paintings and artworks came as late as 2009 [42, 43]. It is clear that due to its unmistaken popularity, despite the known health hazards, lead white was hard to ban from Dutch 20th century oil paintings. Low counts of lead may originate from an added drier rather than from the lead white pigment.

Zinc white and titanium white are a common mixture, and zinc white with lead white is also found possibly as leaded zinc oxide [6]. On the other hand, the combination of lead white and titanium white is only found in grounds (Fig. 3), which may originate from multiple ground layers or mixtures. The subset of impastos does not show a single case of a titanium white/lead white mixture. This is in line with investigated recipes in the Royal Talens and Webber archives [7], where only one recipe called 'mixed white' contains all three white pigments. In this, 1956, Talens recipe titanium white is present as a minor component of the oil paint (ten times less by weight than lead white and zinc white). This finding indicates that if lead and titanium peaks are both identified in an XRF spectrum these elements are likely originating from different layers, with titanium white most likely present in the top layer.

\section{The developments in white paint composition in the 20th century}

Figure 4 shows the PCA scoreplot of the average of the white areas from all paintings, normalized to the maximum peak area. The figure can be interpreted as a reference roadmap for researchers and conservators doing XRF on modern paintings. Figure 5 presents the associated loadings for principal component 1 and 2, which describe $85 \%$ of the variation in the post-processed dataset. The PCA scoreplot shows interesting chronological features discussed below. Before doing so, we would like to underline a number of important caveats. Firstly, clusters based on paint type have been manually defined after coloring the plot for normalized Ti peak areas, normalized $\mathrm{Zn}$ peak areas, normalized $\mathrm{Pb}$ peak areas and normalized ratio: $\mathrm{Ti} /(\mathrm{Ti}+\mathrm{Zn})$, taking into account the signal distortion between $\mathrm{Zn}$ and $\mathrm{Ti}$ peak areas (Additional file 1: Figures S20, S21). Secondly, this analysis does not provide insight into painting stratigraphy, hence combination groups are labelled: mixture or layers.

Figure 4 presents the same trend as previously depicted in Fig. 2, namely of the gradual development from lead white to titanium white via the extensive use of zinc white. It shows interesting cross-connections between artist, time and paint compositions. One important finding is the strong representation of CoBrA artist (Appel, Constant, Corneille, Jorn and others) in the 'Zn paints' section. Zn paints are susceptible to problematic soap formation [19] which may become an even larger problem than already expected.

PCA of the complete dataset shows interesting general chronological trends. However, a closer look at data subsets can be equally interesting. Investigation of the subset of artworks with titanium as the main peak shows an anti-correlation of barium and calcium (Additional file 1: Figure S22). This indicates that in most cases one type of filler or composite pigment base was used. Furthermore, investigating the subset of artworks with zinc as the main peak yield an anti-correlation of titanium and lead (Additional file 1: Figure S22). This observation supports once more that zinc white would either be combined with lead white or with titanium white but not with both.

\section{Looking into the artist studio...}

Another aim of this study was to investigate how the general trends in pigment use relate to individual artists. To this end, we selected three painters/artistic movements represented by a sufficient number of paintings in the dataset. This resulted in three examples: 11 paintings by J.C.J. van der Heyden, 7 paintings by K. van Bohemen and 30 paintings by CoBrA artists Appel, Constant, Corneille, Rooskens and Nieuwenhuis.

\section{van der Heyden}

The paints used by J.C.J. van der Heyden can be clustered in three different categories, Fig. 6a. J.C.J. van der Heyden appears to undergo an identical development in his use of white pigments as the general development in the Netherlands discussed previously. In the 1950s he used lead white and zinc white (either mixed or superimposed), 


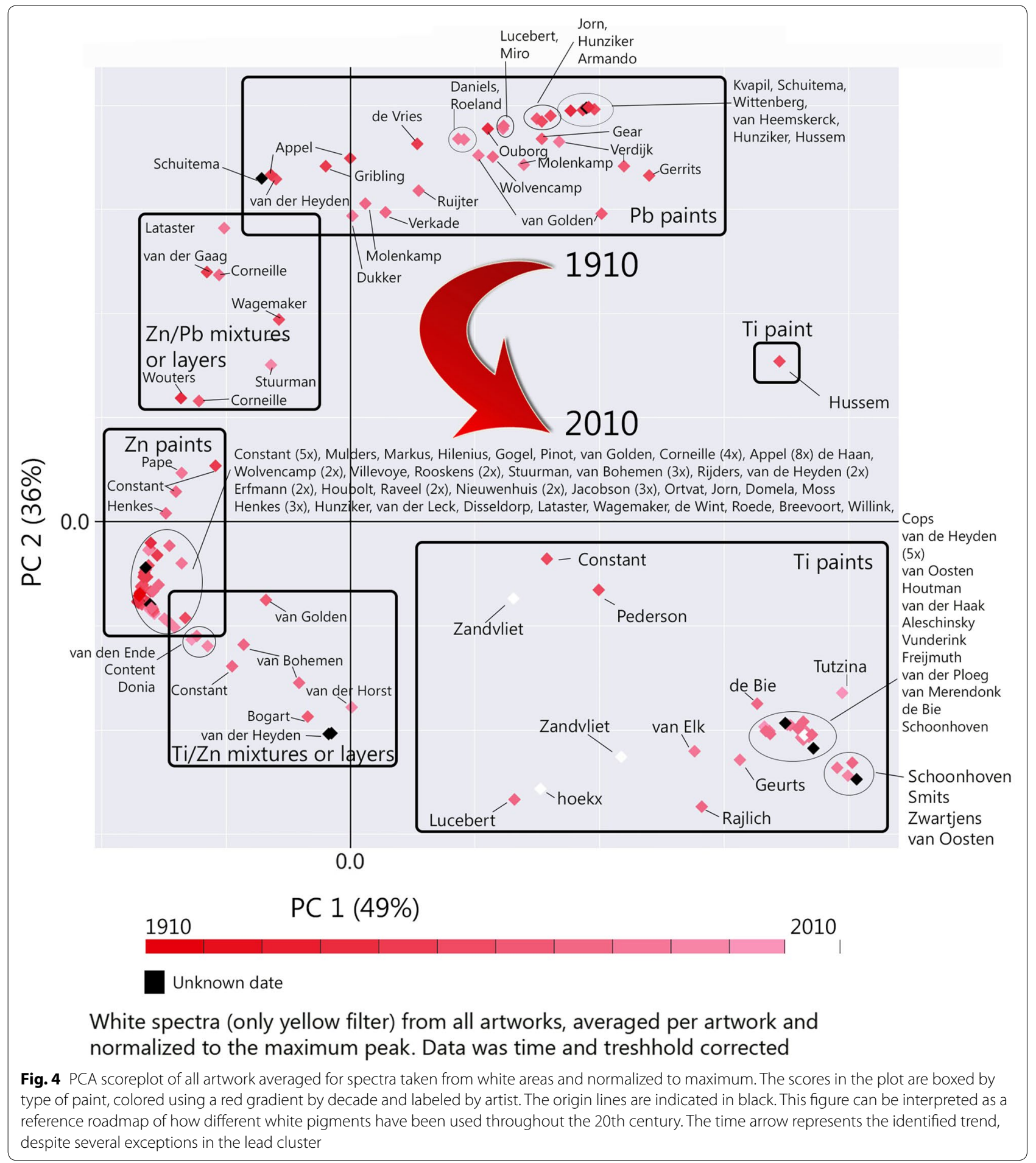

in the 1960s he moves on to use a zinc and barium containing paint (either a mixture of zinc white with barium sulfate or lithopone). Finally, in the 1970s and 1980s, he uses titanium based paints, four of which are in acrylic binders. XRD analysis shows that 'Hellende Horizon', a painting in acrylic from the 1970s, contains rutile, the more stable form of titanium white, and calcium carbonate. This could suggest that the other acrylic paints from that time may have been produced with similar pigments and could be less vulnerable to degradation. The results 


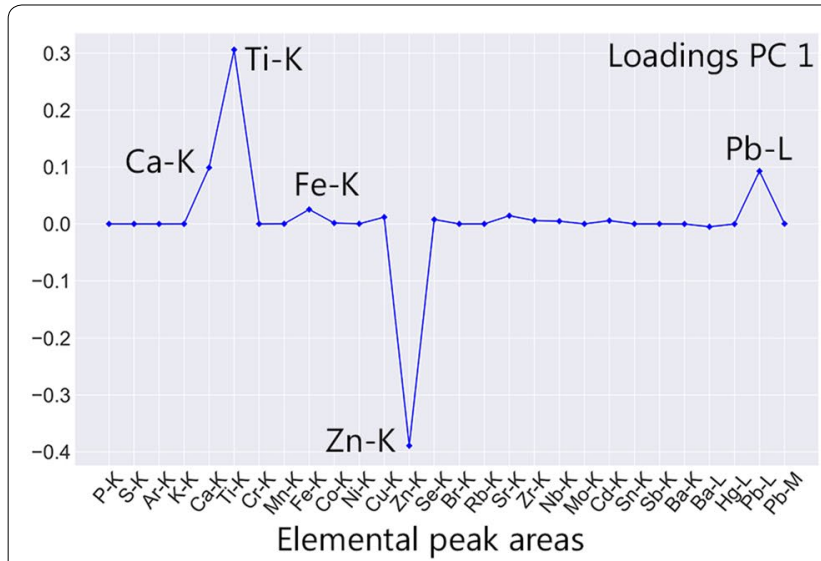

Fig. 5 Loadingplots for PC1 and PC2 corresponding to Fig. 4

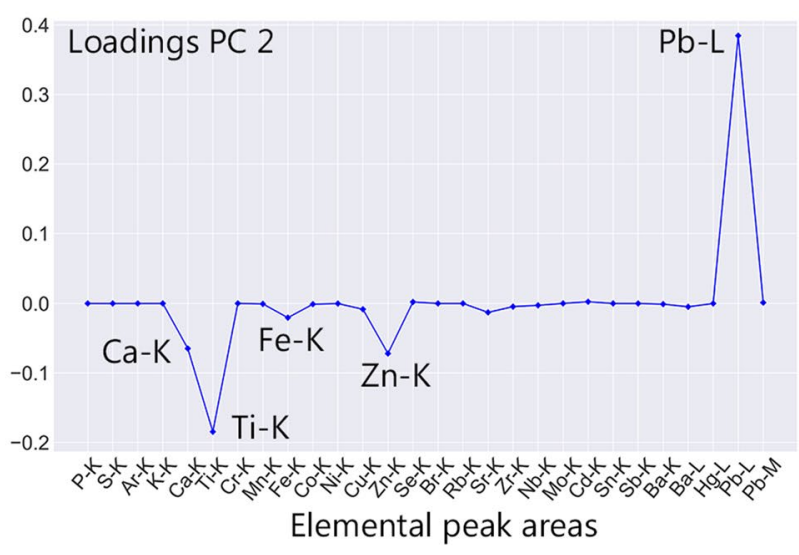

a J.C.J. van der Heyden

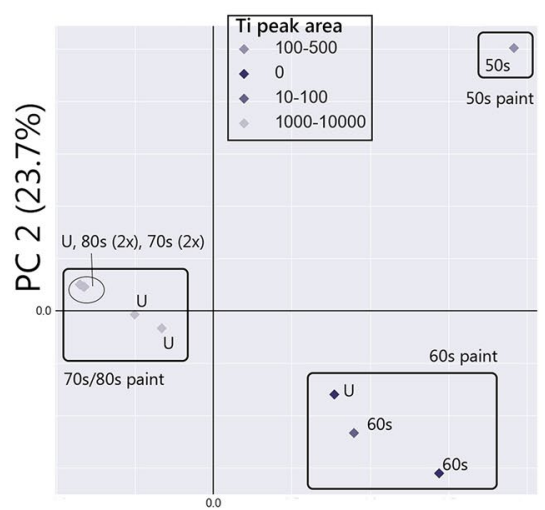

PC 1 (75.8\%)

Loadings PC 1
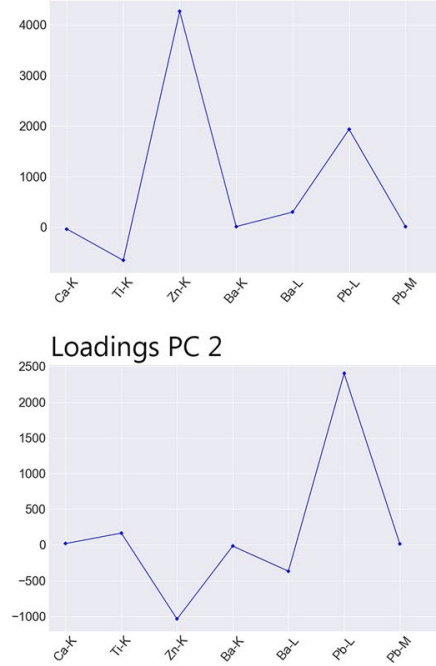

Fig. 6 a PCA scoreplot and loadingplots (PC1 and PC2) of 11 paintings by J.C.J. van der Heyden, averaged over the spectra of the white areas. PCA was done taking only the white elements (Ca, Ti, Ba, Zn, Pb) into account. b Bivariate Ba-L vs Zn-K analysis and PCA scoreplot of 7 paintings by van K. van Bohemen, averaged over the spectra of white areas

\section{b K. van Bohemen}

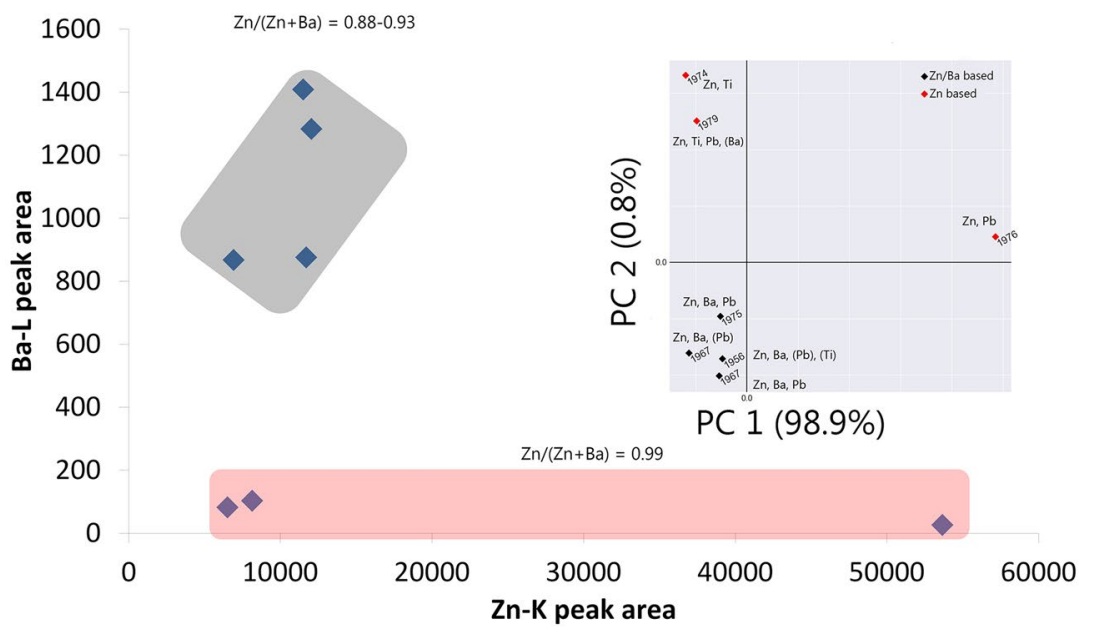

Loadings PC 1
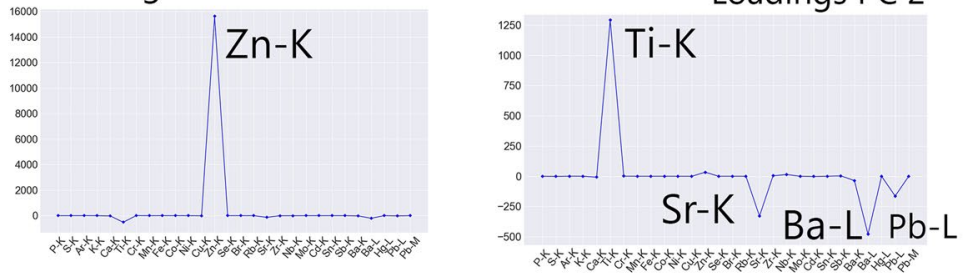


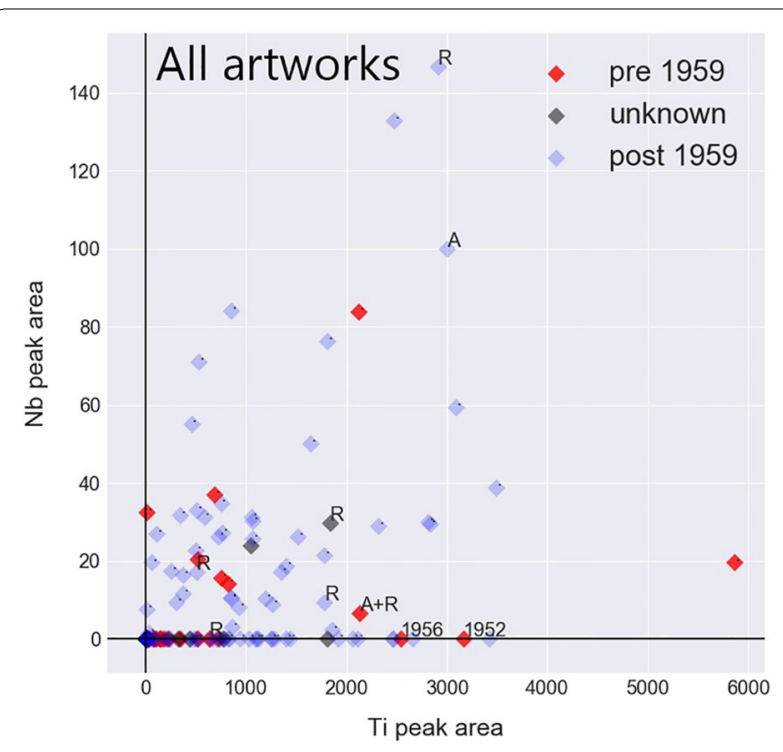

Fig. 7 Scatter plots of niobium K vs titanium K peak areas of all artworks (average value of the spectra taken from white areas) colored by date, related to the date of introduction of the chloride process (1959) and labelled for unexpected dates or, if known, the pigment crystal structure

from this case study coincide with the general trends observed in the full dataset and thus support this method of analysis and data processing.

\section{van Bohemen}

In the case study of the $K$. van Bohemen paintings (by bivariate or PC analysis) two main types of paints can be identified: the zinc oxide based paints (post 1974) and the $\mathrm{Zn} / \mathrm{Ba}$ based paints (up to 1975), Fig. 6b.

The $\mathrm{Zn}$-based paints split into two groups indicating the mixtures of zinc white and titanium white (PCA scoreplot top left) and the mixture of zinc white and lead white (PCA scoreplot right). For this subset, the general trend of $\mathrm{TiO}_{2}$ appearing in the 1970s is confirmed (paintings from 1974 and 1979).

The $\mathrm{Zn} / \mathrm{Ba}$ correlation, in the four black labeled paints (Fig. 6b), suggests the association of zinc and barium either as a mixture or as lithopone (co-precipitate of $\mathrm{BaSO}_{4}$ and $\mathrm{ZnS}$ ). Until 1945, lithopone was a strong competitor for the still developing titanium white pigments in the United States [5]. While the present data cannot differentiate between a mixture of zinc white and barium sulfate or the pigment lithopone, XRD of another sample from a different van Bohemen painting from 1966 indicates the presence of lithopone, placing the pigment on the artist's pallet. Interestingly, investigating a subset, not necessarily requiring $\mathrm{PCA}$, provides information about a paint composition $\left(\mathrm{ZnO}+\mathrm{BaSO}_{4}\right.$ or lithopone $)$ not noticeable in the full dataset (Fig. 4). This highlights the possible benefit of doing further investigation of the data in the future.

\section{CoBrA artists Appel, Constant, Corneille, Rooskens and Nieuwenhuis}

As previously indicated, in this study it was found that CoBrA artists often used zinc white. To investigate this further, PCA was applied on a subset of 30 paintings by five CoBrA artists. The results indicated that the main difference between the paints was the zinc to lead ratio. While most paintings contain mainly zinc white, there is a selection of paintings containing zinc white and lead white. In this dataset, neither the date nor the artist coincides with the type of paint used therefore the visualization is omitted. This suggests random pigment choice in the CoBrA group. However, this did not compromise the detection of general trends in the full dataset.

\section{Trace element indicators}

The exploration of the data also resulted in the identification of two possibly indicative and characteristic trace elements: niobium and zirconium.

The determination of the crystal structure of titanium white in paintings is the first step towards a possible risk assessment. However, XRF cannot determine the difference between rutile and anatase and less available techniques such as Raman and XRD are required. Our dataset indicates an association between titanium and niobium, Fig. 7. With one exception, niobium is only present if titanium is also present. Niobium is a characteristic element associated with ore impurities and is impossible to remove via the sulfate process [15], the earliest production process of titanium white pigments.

STEM-EDX confirms that indeed niobium and titanium are associated, ${ }^{6}$ Fig. 8 . The chloride process, started to be developed in 1948 (pilot plant) and a full-scale production facility was opened in 1959 by E.I du Pont de Nemours and Co., Tennesee. In Europe a production facility producing chloride processed rutile opened in 1965 (British Titan Products-one of the suppliers for Winsor and Newton paints) [1,5]. While both processes can theoretically produce both crystal structures, generally the chloride process is used to produce the more stable rutile (developed in the 1940s). Hence the absence of niobium and thus the use of the chloride process can be an indication of the presence of rutile and dates the pigment to post 1959 (or post 1965 in Europe). The presence of niobium is related to the sulfate process which is still in use today. Therefore this can indicate both types of

\footnotetext{
6 The association of titanium and niobium has also been confirmed in the scope of another study (manuscript in preparation) by ICP-OES analysis.
} 


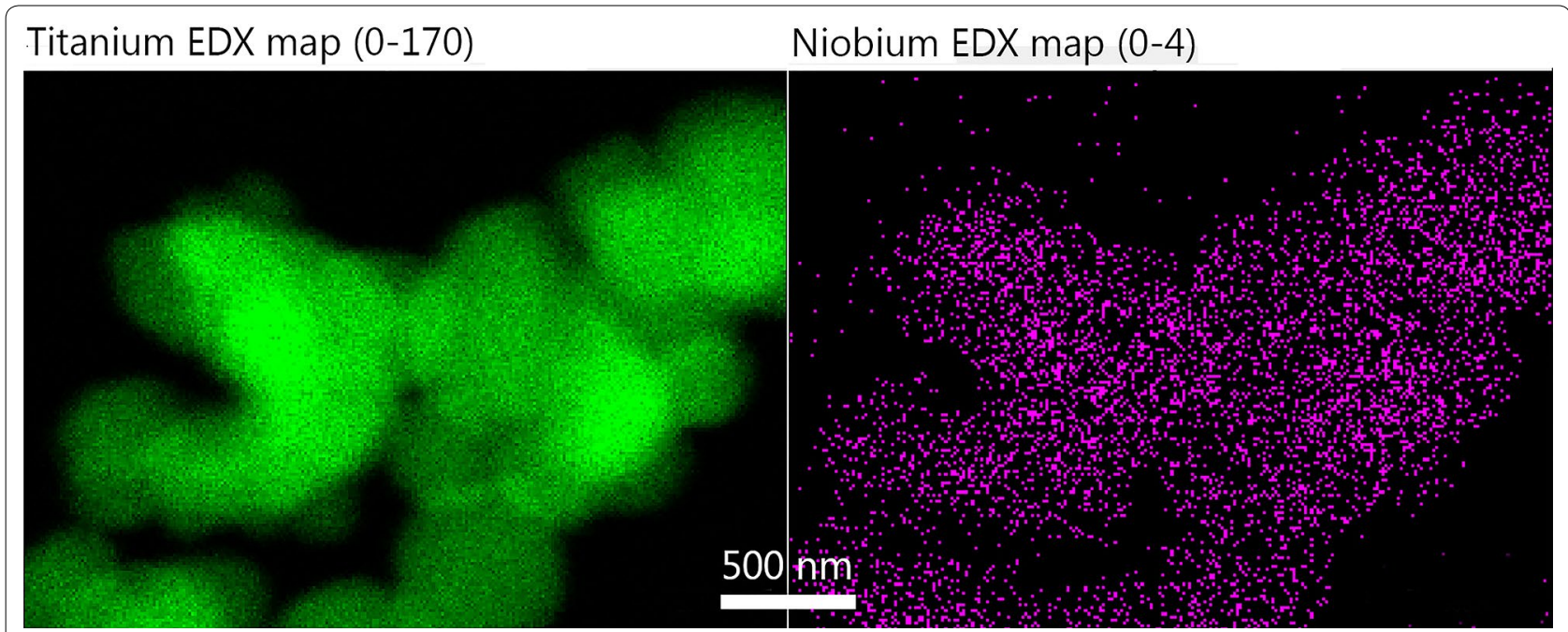

Fig. 8 STEM-EDX map of Titanium dioxide pigment containing niobium impurity (powder: RCE9649 from RCE reference collection). The intensity range of EDX detection for $\mathrm{Ti}$ and $\mathrm{Nb}$ respectively are provided between brackets in the figure header

titanium dioxide pigment and any production date. Comparing the crystal structure analyzed by XRD from micro-samples, with the scatter plot (Fig. 7) confirms this.

It should be noted that implementing the dating, colored as 'pre' or 'post' 1959 in Fig. 7, presents some challenges. Several paintings, painted before 1959, show the absence of niobium. The amount of niobium left in the pigments is dependent on the ilmenite ore. For instance Norwegian ilmenite (containing 0.007\% Nb) results in pigments with $0.012 \% \mathrm{Nb}$, while Australian ilmenite (containing $0.10 \% \mathrm{Nb}$ ) results in pigments with $0.22 \% \mathrm{Nb}$ [1]. While the low niobium contents in titanium white derived from the Australian ilmenite should still be detectable by pXRF [44], some factors may inhibit the detection of niobium with XRF in sulfate processed titanium dioxide. This likely due to the paint composition, detection limit, set threshold $(15 \mathrm{cnt} / \mathrm{s})$, the measurement settings and subsequent signal-to-noise ratio. When the titanium counts are low, inherently the niobium counts will be low and possibly undetected. Similarly, when titanium is not the main peak but zinc or lead are strongly emitting the $\mathrm{Nb}$ signal may get lost in the noise (this is the case for the two red dots labelled 1956 and 1952). The latter was confirmed by investigating the reference material (Additional file 1: Figures S23, S24). In the scatter plot of the small dataset of all impasto's the correlation is clearer and dating is consistent, which supports the idea that in some cases $\mathrm{Nb}$ is not detected, even though it is present. To confirm the absence or presence of niobium, and thus get an indication of crystal structure and dating, analytical improvement is required. In the case of the Bruker III-SD, this can be reached using the $\mathrm{Cu} / \mathrm{Ti} / \mathrm{Al}$ (green) filter with a voltage of $40 \mathrm{kV}$, a current of $15 \mu \mathrm{A}$ and a measurement time of at least $120 \mathrm{~s}$ [45].

Similar to niobium, zirconium is almost never present without titanium. Zirconium can originate, among others, from the paint drier or from a pigment coating on the titanium white that decreases its photocatalytic activity [46]. The simultaneous absence of zirconium and titanium suggest that if present, this indicates either an increased amount of drier (due to slow drying properties of titanium whites) or the detection of the inorganic coating. With the present dataset, using pXRF, the origin of the zirconium cannot be unambiguously determined.

Nevertheless, if zirconium can be related to the presence of a pigment coating, which results in reduced photocatalytical activity, this is of interest from a risk management perspective.

Further research should be performed, which notably entails optimizing pXRF settings as well as using a specifically designed set of reference material.

\section{Conclusions and outlook}

This explorative study has provided new insights into the use of white pigments in the 20th century in the Netherlands. While pXRF is a widely used technique, it was not previously used to record and compare spectra of a large and diverse paintings dataset collected over a substantial amount of time.

Interestingly, our data has shown that the use of white pigments in the Netherlands is clearly different from the general assumption of the international use which seems 
to have a geographical bias toward the United States. It has been demonstrated that, instead of an immediate popularization of titanium white, the pigment entered the market rather slowly and initially predominantly in non-oil binders. The rather late rise of titanium white pigments in the Netherlands, starting from the fifties and stabilizing a secure position in the seventies, reduces the risk of photocatalytic binder degradation for Dutch modern art collections. At the time, improved pigments were on the market, thus increasing the odds that they were used in artists paints. Nevertheless, anatase was used by some Dutch manufacturers until the nineties and surface treatments were not always applied and still under development. Therefore, surveying and monitoring modern art collection for the use of potentially photocatalytically active pigments remains of high importance.

Zinc white was very popular in the mid-20th century, especially used by CoBrA artists and even lead white remained a popular artist pigment despite its known toxicity well into the 20th century. Both these pigments are not without risks either and have been reported in relation to problematic soap formation.

What is more, investigating subsets of one or more artists can provide insight into personal artist development, in terms of materials' use. This is clear for J.C.J. van der Heyden who follows the broader trend of using lead and zinc white in the fifties, zinc base paints in the sixties and titanium white based (acrylic) paints in the seventies and eighties.

Additionally, this study reveils that niobium, detectable by pXRF, may be a very useful marker to determine the production process and its absence can point to a post 1959 dating as well as to the rutile crystal structure. Rutile is considered to be more stable and is often found with a stabilizing inorganic coating. In other words, this provides an accessible, cheap and easy to use technique to make an initial classification of vulnerabilty to photocatalysis of a painting.

The trends brought about in the present study are in line with information from archives as well as the single-artist case-studies. In other words, despite the use of two instruments, the slightly different experimental conditions, the minimally restricted selection of objects and the experimental noise, this exploratorive study was useful and provided new insight. For the identification of more detailed developments in the use of white pigments, the dataset should be extended, focused on impasto areas and preferably art historically balanced. Involving more museums to gather a larger dataset of XRF spectra and metadata of white paints (or any color for that matter) would make this study more robust as a potential tool for risk analysis of the (white) paints in (Dutch) collections. Furthermore, multivariate data analysis via PCA in this study was mostly used for a visualization purpose. The dataset likely contains more information than was extracted in this study. Therefore, to answer other questions, outside the scope of this work, the dataset may be further analyzed in the future. Several options to explore are: analysis on the raw spectra rather than peak areas; analysis on each separate paint area rather than on the averaged peak areas; and other types of data analysis such as t-Distributed Stochastic Neighbor Embedding (T-SNE), independent component analysis (ICA) or nonnegative matrix factorization (NMF).

\section{Additional file}

Additional file 1. Additional tables and figures.

\section{Authors' contributions}

BAVD performed all experiments and data interpretations and wrote and adjusted the manuscript according to co-authors suggestions. VDB and JD supervise BAVD Ph.D. and contributed to the final manuscript. JG helped us to re-evaluate the data and clarified some chemometrical and data analytical aspects during the revision of the manuscript. All authors read and approved the final manuscript.

\section{Author details}

${ }^{1}$ Rijksmuseum Amsterdam, Hobbemastraat 22, 1071 ZC Amsterdam, The Netherlands. ${ }^{2}$ Cultural Heritage Agency of the Netherlands, Hobbemastraat 22, 1071 ZC Amsterdam, The Netherlands. ${ }^{3}$ Materials for Arts and Archeology, 3ME, TU Delft, Mekelweg 2, 2628 CD Delft, The Netherlands. ${ }^{4}$ AkzoNobel, Supply Chain, Research \& Development, Expert Capability Group-Measurement \& Analytical Science, Zutphenseweg 10, 7418 AJ Deventer, The Netherlands.

\section{Acknowledgements}

This work has been financially and experimentally supported by AkzoNobel and hosted by the Rijksmuseum Amsterdam. Additionally Prof. P.J. Kooyman is acknowledged for the involvement in van Driels Ph.D. research.

The cultural heritage agency of the Netherlands (RCE) and Dennis Breakmans, formally at Delft University of Technology, are acknowledged for the use of the XRF instrumentation.

The Dutch association for company art collections (VBCN, Vereniging bedrijfscollecties Nederland) is acknowledged for forwarding my analysis request to the Dutch company collections associated with them. The following collections and people are acknowledged for providing access and support during data acquisition: Sabrina Kamstra at the AMC Kunstcollectie, Hilde de Bruijn at the Cobra Museum Amstelveen, Ruth Hoppe at the Gemeentemuseum, Annelies Koldeweij at the ING Art Collection, Anita Jansen, Ron Stokhof and Mark Boers at Museum Prinsenhof Delft, Caroline Coffrie at the Bouwfonds kunstcollectie, Zeph Benders and Yuri van der Linden at the RCE collection, Colin Huizing and Marco Steketee at the Stedelijk museum Schiedam, Femke van der Knaap at Boeijink, Boekel \& vander Knaap Schilderijen restautie; Lise Steyn at the university of Amsterdam (UVA) and at the RCE; Maranthe Lamers formaly at the UvA (PI student), freelancers Marya Albrecht, Jorinde Koenen, Annelies van Hoesel and Lydia Beerkens.

Furthermore we thank the RCE interns Rose Heaton, Rika Pause and Nathalie de Vries for their help during data aquisition and RCE scientist Luc Megens for his training on the XRD and many discussions about the topic of XRF. Similarly, we thank Ana Martins at the MoMA for the discussions we had about XRF and multivariate data analysis. At AkzoNobel Brenda Rossenaar and Wilma Ravesloot are acknowledged for STEM-EDX sample preparation and analysis. Arie Pappot and Rob Erdmann at the Rijksmuseum respectively helped me with the PyMCA deconvolution and the use of Python for data analysis.

\section{Competing interests}

The authors declare that they have no competing interests. 


\section{Availability of data and materials}

The reference materials can be accessed by contacting the authors at the Cultural Heritage Agency of the Netherlands. The data is not accessible at the moment as agreements need to be established with the collections involved. Please contact the author to discuss this.

\section{Ethics approval and consent to participate}

\section{Not applicable.}

\section{Funding}

van Driel's Ph.D. is funded by AkzoNobel. The research presented in the paper was performed with support from AkzoNobel researchers Jan Gerretzen, Brenda Rossenaar and Wilma Ravesloot.

\section{Publisher's Note}

Springer Nature remains neutral with regard to jurisdictional claims in published maps and institutional affiliations.

\section{Received: 24 October 2017 Accepted: 4 February 2018}

Published online: 29 March 2018

\section{References}

1. Laver M. Titanium white. In: West FitzHugh E, editor. Artists' pigments: a handbook of their history and characteristics, vol. 3. London: National gallery of Art, Archetype Publications; 1997. p. 295-355.

2. Markowitz G, Rosner D. History and perspective on lead. http://www. toxipedia.org/display/toxipedia/History+and+Perspectives+on+Lead. Accessed Nov 2014

3. Bacci M, Picollo M, Trumpy G, Tsukada M, Kunzelman D. Non-invasive identification of white pigments on 20th-century oil paintings by using fiber optic reflectance spectroscopy. JAIC. 2007:46(1):27-37.

4. Brunner H. Pitture. In: Singer C, Holmyard AJ, Hall AR, Williams T, editors. Storia della tecnologia, vol. 6. Turin: Bollati Boringhieri; 1982. p. 617-31.

5. Stieg FB. Opaque white pigments in coatings. ACS Appl Polym Sc. 1985;285:1249-69.

6. Kuhn H. Zinc oxide. In: Feller RL, Roy A, editors. Artists' pigments: a hand book of their history and characteristics. London: Cambridge University Press; 1986. p. 169-86

7. Phenix A, van den Berg KJ, Soldano A, van Driel BA. The might of white: formulations of titanium dioxide-based oil paints as evidenced in archives of two artists' colourmen mid-twentieth century. In: ICOM-CC triennial conference 2017, Copenhagen. 2017.

8. van den Berg KJ, Miliani C, Aldrovandi A, Brunetti BG, de Groot S, Kahrim $\mathrm{K}$, et al. The chemistry of Mondrian's paints in Victory Boogie Woogie. In: van Bommel MR, Janssen H, Spronk R, editors. Inside Out Victory Boogie Woogie. Amsterdam: Haags Gemeentemuseum, Amsterdam University Press; 2012

9. Martins A, Albertson C, McGlinchey C, Dik J. Piet Mondrian's Broadway Boogie Woogie: non-invasive analysis using macro X-ray fluorescence mapping (MA-XRF) and multivariate curve resolution-alternating least square (MCR-ALS). Heritage Sci. 2016;4:22

10. van Bommel MR, Janssen H, Sponk R. Victory Boogie Woogie uitgepakt. 1st ed. Amsterdam: Haags Gemeentemuseum and Amsterdam University Press; 2012

11. Linton J. The white test... 5 years in the making. http://blog.jonathanlinton.com/2010/05/white-test-5-years-in-making.html. Accessed Nov 2014

12. Sims E. White is white, right? https://heymaryemma.wordpress.com/ Accessed Nov 2014.

13. Mancine-Hresko L. White test. 2013. http://leomancinihresko.com/whitetest-2013/. Accessed Nov 2014.

14. DuPont Magazine. 1935. http://digital.hagley.org/islandora/object/ islandora\%3A1979489. Accessed Nov.

15. Braun $\mathrm{JH}$, Baidins $\mathrm{A}$, Marganski RE. TiO 2 pigment technology: a review. Prog Org Coat. 1992;20(2):105-38.

16. van Driel BA, WezendonkTA, van den Berg KJ, Kooyman PJ, Gascon J, Dik $J$. Determination of early warning signs for photocatalytic degradation of titanium white oil paints by means of surface analysis. Spectrochim Acta A. 2017:172:100-8.
17. Völz HG, Kaempf G, Fitzky HG, Klaeren A. The chemical nature of chalking in the presence of titanium dioxide pigments. ACS Photodegrad Photostab Coat. 1981;151:163-82.

18. Morsch S, van Driel BA, van den Berg KJ, Dik J. Investigating the photocatalytic degradation of oil paint using ATR-IR and AFM-IR. ACS Appl Mater Interfaces. 2017;9(11):10169-79.

19. Hermans JJ. Metal Soaps in oil paint, structure mechanisms and dynamics. Ph.D. thesis at Van't Hoff Institute for Molecular Sciences, Universiteit van Amsterdam. 2017. ISBN: 978-94-629-5578-3 http://hdl.handle. net/11245.1/53663926-183c-40aa-b7b3-e6027979cb7d. Accessed Sept 2017.

20. McGlinchey C. Handheld XRF for the examination of paintings: proper use and limitations. In: Shugar AN, Mass JL, editors. Handheld XRF for art and archaeology (studies in archeological sciences), vol. 4. Leuven: Leuven University Press; 2013.

21. Namowicz C, Trentelman K, McGlinchey C. Erratum: XRF of cultural heritage materials: Round-robin IV_ paint on canvas. Powder Diffr. $2009 \cdot 24 \cdot 124-9$

22. Stulik DC, Kaplan A. Application of a handheld XRF spectrometer in research and identification of photographs. In: Handheld XRF for art and archaeology, vol. 3. Leuven: Leuven University Press. 2012; p. 75-130.

23. Alfeld M, Pedroso JV, Eikema M, Hommes G, van der Snickt G, Tauber G, et al. A mobile instrument for in situ scanning macro-XRF investigation of historical paintings. J Anal Atomic Spectrom. 2013;28:760-7.

24. Szökefalvi-Nagy Z, Demeter I, Kocsonya A, Kovacs I. Non-destructive XRF analysis of paintings. Nucl Instrum Methods Phys Res B. 2014:226(1-2):53-9.

25. Solé VA, Papillon E, Cotte M, Walter P, Susini J. A multiplatform code for the analysis of energy-dispersive $\mathrm{X}$-ray fluorescence spectra. Spectrochim Acta B. 2007;62(1):63-8

26. Rosi F, Burnstock A, van den Berg KJ, Miliani C, Brunetti BG, Sgamellott A. A non-invasive XRF study supported by multivariate statistical analysis and reflectance FTIR to assess the composition of modern painting materials. Spectrochim Acta A. 2009;71(5):1655-62.

27. Appoloni CR, Melquiades FL. Portable XRF and principal component analysis for bill characterization in forensic science. Appl Radiat Isot. 2014;85:92-5.

28. Martins A, Coddington J, van der Snickt G, van Driel BA, McGlinchey C, Dahlberg D, Janssens J, Dik J. Jackson Pollock's Number 1A, 1948: a noninvasive study using macro-X-ray fluorescence mapping (MA-XRF) and multivariate curve resolution-alternating least squares (MCR-ALS) analysis. Heritage Sci. 2016:4(1):33

29. Capobianco G, Pelosi C, Agresti G, Bonifazi G, Santamaria U, Serranti S. $X$-ray fluorescence investigation on yellow pigments based on lead, tin and antimony through the comparison between laboratory and portable instruments. J Cult Heritage. 2018;29:19-29.

30. Papachristodoulou C, Oikonomou A, loannides K, Gravani K. A study of ancient pottery by means of $\mathrm{X}$-ray fluorescence spectroscopy, multivariate statistics and mineralogical analysis. Anal Chim Acta. 2006;573-574:347-53.

31. Kessler T, Hoffmann P, Greve T, Ortner HM. Optimization of the identification of chemical compounds by energy-dispersive $\mathrm{X}$-ray fluorescence spectrometry and subsequent multivariate analysis. X-ray Spectrom. 2002;31(5):383-90.

32. Sciutto G, Oliveri P, Prati S, Quaranta M, Bersani S, Mazzeo R. An advanced multivariate approach for processing $X$-ray fluorescence spectral and hyperspectral data from non-invasive in situ analyses on painted surfaces. Anal Chim Acta. 2012;752:30-8

33. Alberghina MF, Barraco R, Brai M, Schillaci T, Tranchina L. Integrated analytical methodologies for the study of corrosion processes in archaeological bronzes. Spectrochim Acta B. 2012;66(2):129-37.

34. Alfeld M, Wahabzada M, Bauckhage C, Kersting K, Wellenreuther F, Falkenberg G. Non-negative factor analysis supporting the interpretation of elemental distribution images acquired by XRF. J Phys Conf Ser. 2014;499(1):012013

35. Lopes F, Melquiades FL, Appoloni CR, Cesareo R, Rizzutto M, Silva TF. Thickness determination of gold layer on pre-Columbian objects and a gilding frame, combining $\mathrm{PXRF}$ and PLS regression. X-ray Spectrom. 2016;45(6):344-51.

36. van der Snickt G, Janssens K, Schalm O, Aibeo C, Kloust H, Alfeld M. James Ensor's pigment use: artistic and material evolution studied by 
means of portable X-ray fluorescence spectrometry. X-ray Spectrom. 2010;39(2):103-11.

37. Burnstock A, van den Berg KJ, van der Gurp F, Bayliss S, Klein-Ovink B. Making paint in the 20th century: the Talens Archive. In: Eyb-Green S, Townshend JH, Pilz K, Kroustallis S, van Leeuwen I, editors. Sources in art technology, back to basics. Archetype. 2016; p. 43-50.

38. de Keijzer M. The history of modern synthetic inorganic and organic artists' pigments. In: Contributions to conservation at the Netherlands Institute for Cultural Heritage, James \& James (Science Publishers) Ltd. 2002

39. Doerner M, Hoppe T. Malmaterial und seine Verwendung im Bilde. ISBN 13: 9783432017174.1928

40. Fischer M. The permanent palette. New York: National Publishing Society; 1930

41. de Keijzer M. Apropos of titanium white. Restauro. 1989;95(3):214-7.

42. Dodelijk mooi. Cultural heritage agency of the Netherlands. http://www. kleurenvisie.nl/db/upload/documents/kleur_in_de_media/Dodelijk_ mooi_RCE_1_2012.pdf. Accessed Sept 2017.
43. Loodwit symposium - Geen witte onschuld, een blik op internationale loodwit regelgeving. http://www.collectiewijzer.n//2012/01/12/loodwitsymposium-geen-witte-onschuld-een-blik-op-internationale-loodwitregelgeving-2/. Accessed Sept 2017.

44. Williams-Thorpe $\mathrm{O}$. The application of portable $\mathrm{X}$-ray fluorescence analysis to archaeological lithic provenancing. In: Potts PJ, West M, editors. Portable X-ray fluorescence spectrometry: capabilities for in situ analysis, chapter 8. London: The Royal Society of Chemistry; 2008. p. 174-205.

45. Speakman SA. Using the Bruker Tracer III-SD handheld X-ray fluorescence spectrometer using PC software for data collection. http://prism.mit.edu/ xray/oldsite/Bruker\%20XRF\%20SOP.pdf. Accessed 2015.

46. Zirconium compounds in paint. Pigment Resin Technol. 1978;7(9):15-17. https://www.emeraldinsight.com/doi/abs/10.1108/eb041421?journalCo de $=$ prt

\section{Submit your manuscript to a SpringerOpen ${ }^{\circ}$ journal and benefit from:}

- Convenient online submission

- Rigorous peer review

- Open access: articles freely available online

- High visibility within the field

- Retaining the copyright to your article

Submit your next manuscript at $\mathbf{s p r i n g e r o p e n . c o m ~}$ 